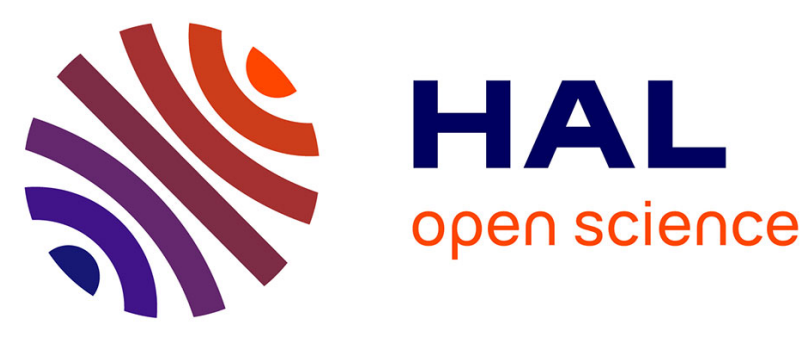

\title{
Antimicrobial resistance in colonizing group B Streptococci before the implementation of a Swedish intrapartum antibiotic prophylaxis program
}

M. Granlund, P. Axemo, K. Bremme, A.-L. Bryngelsson, M. Carlsson Wallin, C.-M. Ekström, S. Håkansson, B. Jacobsson, K. Källén, E. Spetz, et al.

\section{To cite this version:}

M. Granlund, P. Axemo, K. Bremme, A.-L. Bryngelsson, M. Carlsson Wallin, et al.. Antimicrobial resistance in colonizing group B Streptococci before the implementation of a Swedish intrapartum antibiotic prophylaxis program. European Journal of Clinical Microbiology and Infectious Diseases, 2010, 29 (10), pp.1195-1201. 10.1007/s10096-010-0877-3 . hal-00614611

\author{
HAL Id: hal-00614611 \\ https://hal.science/hal-00614611
}

Submitted on 13 Aug 2011

HAL is a multi-disciplinary open access archive for the deposit and dissemination of scientific research documents, whether they are published or not. The documents may come from teaching and research institutions in France or abroad, or from public or private research centers.
L'archive ouverte pluridisciplinaire HAL, est destinée au dépôt et à la diffusion de documents scientifiques de niveau recherche, publiés ou non, émanant des établissements d'enseignement et de recherche français ou étrangers, des laboratoires publics ou privés. 
Diseases

Editorial Manager(tm) for European Journal of Clinical Microbiology \& Infectious

Manuscript Draft

Manuscript Number: EJCMID-D-09-00523R1

Title: Antimicrobial resistance in colonizing Group B Streptococci before implementation of a Swedish intrapartum antibiotic prophylaxis program

Article Type: Article

Keywords: GBS, Antibiotic Susceptibility testing, Swedish parturients.

Corresponding Author: Dr Margareta Granlund, MD, PhD

Corresponding Author's Institution: Clinical Microbiology

First Author: Margareta Granlund, MD, PhD

Order of Authors: Margareta Granlund, MD, PhD; Pia Axemo, MD, PhD; Katarina Bremme, MD, PhD;

Anna-Lena Bryngelsson, MD; Marie Carlsson Wallin, MD; Carl-Magnus Ekström, MD; Stellan Håkansson, MD, PhD; Bo Jacobsson, MD, PhD; Karin Källén, PhD; Eva Spetz, MD

Abstract: The prevalence of antibiotic resistance and their genetic determinants in colonizing group B streptococci (GBS) sampled in a Swedish nationwide survey was examined. In five GBS isolates (1,3 \%) kanamycin/amikacin resistance and presence of the aphA-3 gene was identified. Three of these isolates carried the aad-6 gene and were streptomycin resistant. Screening with kanamycin and streptomycin $1000 \mu \mathrm{g}$ disks enabled a rapid and easy detection of these isolates. In all 312/396 (79\%) GBS were tetracycline resistant and $95 \%$ of examined isolates harboured the tetM gene. Among the 22 (5.5\%) GBS resistant to erythromycin and/or clindamycin, the ermB gene was detected in nine isolates $(41 \%)$ and erm(A/TR) in ten isolates (45\%). High level of erythromycin and clindamycin resistance with MICs $>256 \mathrm{mg} / \mathrm{L}$ was found in four serotype $\mathrm{V}$ isolates that harboured ermB. The erythromycin/clindamycin resistance was distributed among all the common serotypes Ia, Ib, II, III, IV and $\mathrm{V}$ but not present in any of 44 serotype III isolates, associated to clonal complex 17. Screening for penicillin resistance with $1 \mu \mathrm{g}$ oxacillin disks showed a homogenous population with a mean inhibition zone of $20 \mathrm{~mm}$. A change in the present oxacillin breakpoints for GBS is suggested.

Response to Reviewers: Dear Reviewers,

We have now tried to improve the paper: Antimicrobial resistance in colonizing Group B Streptococci before implementation of a Swedish intrapartum antibiotic prophylaxis program, according to your valuable suggestions.

Reviewer 1:

Introduction: the last five lines have been removed.

Material and methods: The abbreviation for SRGA is included. The sentence about aad- 6 has been altered and the erronous amount of Ampli-Taq Gold has been changed.

Results: The number of isolates with tetO and lack of tetO or tetM is given. Table I is rewritten and the number of ermA/TR is corrected. 
The mobile elements GBSi1 and IS1548 is now presented in the Material and methods section, and the results of the characterization of the serotype III isolates in relation to the antibiotic resistance pattern is given in the result section and dicussed in the Discussion part.

The penicillin G MIC should be $0,032 \mathrm{mg} / \mathrm{L}$, which now is corrected. The gene product of aad -6 is hopefully now better described.

Discussion: Section 2; the part about the erronous penicillin E-test is removed.

The Tables are rewritten and Figure 1 is omitted.

Reviewer 2.

We have tried to shorten the manuscript and have also made an effort to include data from AST with the EUCAST method on selected isolates.

Materials and methods: The part discussing the prevoiusly published material has been extended including the methods for serotyping and MLST.

Results: The paragraph on macrolide resistance has been rewritten and in addition to disk diffusion according to EUCAST MICs were determined. Since this gave new results, which showed a high-level of MLS resistance in four serotype $V$ isolates these data are now presented in the result section. In the part regarding screening for penicillin resistance ceftibuten was included together with oxacillin in the disk diffusion made according to EUCAST. That test was made on 24 isolates with oxacillin inhibition zones on ISA-NAD $<18,5 \mathrm{~mm}$ since ceftibuten disk diffusion results recently has been suggested to have $100 \%$ sensitivity and specificity for detection of penicillin resistance in GBS (Kimura et al, ref.25).

Figure 1 is omitted, the tables I and II have been rewritten as well as the reference list. 


\title{
Antimicrobial resistance in colonizing Group B
}

\section{Streptococci before implementation of a Swedish}

\section{intrapartum antibiotic prophylaxis program}

\begin{abstract}
Authors: M. Granlund MD, $\mathrm{PhD}^{1 *}$, P. Axemo, MD, $\mathrm{PhD}^{2}$, K. Bremme, MD, PhD ${ }^{3}, \mathrm{~A}-\mathrm{L}$ Bryngelsson, $\mathrm{MD}^{4}, \mathrm{M}$. Carlsson Wallin, $\mathrm{MD}^{5}, \mathrm{C}-\mathrm{M}$ Ekström, $\mathrm{MD}^{6}$, S. Håkansson, $\mathrm{MD}, \mathrm{PhD}^{7}$, B. Jacobsson, $\mathrm{MD}, \mathrm{PhD}^{8}$, K. Källén, $\mathrm{PhD}^{9}$, E. Spetz, $\mathrm{MD}^{10}$, I. Tessin, $\mathrm{MD}$, $\mathrm{PhD}^{11}$,

(The Swedish working group for prevention of perinatal group $\mathrm{B}$ streptococcal infections)
\end{abstract}

${ }^{1}$ Department of Clinical Bacteriology, Umeå University Hospital, Umeå

${ }^{2}$ Department of Obstetrics and Gynecology, Academic Hospital Uppsala

${ }^{3}$ Department of Obstetrics and Gynecology, Karolinska University Hospital, Stockholm

${ }^{4}$ Department of Obstetrics and Gynecology, University Hospital, Örebro

${ }^{5}$ Department of Obstetrics and Gynecology, Ystad Hospital, Ystad

${ }^{6}$ Department of Obstetrics and Gynecology, Vrinnevi Hospital, Norrköping

${ }^{7}$ Department of Pediatrics, University Hospital, Umeå

${ }^{8}$ Department of Obstetrics and Gynecology, Sahlgrenska University Hospital, Göteborg

${ }^{9}$ Department of Reproductive Epidemiology, Tornblad Institute, Lund University, Lund

${ }^{10}$ Department of Obstetrics and Gynecology, Östersund Hospital, Östersund

${ }^{11}$ Department of Pediatrics, Queen Silvia Children's Hospital, Göteborg.

${ }^{*}$ Corresponding author:

Margareta Granlund, MD, PhD

Phone: +46 (0)9078517 72

Department of Clinical Bacteriology,

Fax: +46 (0)907853591

Umeå University Hospital

Email: Margareta.Granlund@climi.umu.se

SE-901 85 Umeå

SWEDEN

Keywords:

GBS, Antibiotic Susceptibility testing, Swedish parturients. 


\section{Abstract}

The prevalence of antibiotic resistance and their genetic determinants in colonizing group $B$ streptococci (GBS) sampled in a Swedish nationwide survey was examined. In five GBS isolates (1, 3 $\%)$ kanamycin/amikacin resistance and presence of the aphA-3 gene was identified. Three of these isolates carried the aad- 6 gene and were streptomycin resistant. Screening with kanamycin and streptomycin $1000 \mu \mathrm{g}$ disks enabled a rapid and easy detection of these isolates. In all 312/396 (79 \%) GBS were tetracycline resistant and $95 \%$ of examined isolates harboured the tetM gene. Among the $22(5.5 \%)$ GBS resistant to erythromycin and/or clindamycin, the ermB gene was detected in nine isolates (41\%) and erm(A/TR) in ten isolates (45\%). High level of erythromycin and clindamycin resistance with MICs $>256 \mathrm{mg} / \mathrm{L}$ was found in four serotype $\mathrm{V}$ isolates that harboured ermB. The erythromycin/clindamycin resistance was distributed among all the common serotypes la, Ib, II, III, IV and $\mathrm{V}$ but not present in any of 44 serotype III isolates, associated to clonal complex 17 . Screening for penicillin resistance with $1 \mu \mathrm{g}$ oxacillin disks showed a homogenous population with a mean inhibition zone of $20 \mathrm{~mm}$. A change in the present oxacillin breakpoints for GBS is suggested.

\section{Introduction}

Group B streptococci (GBS) are recognized as a common cause of life-threatening infections in neonates. When the mother carries GBS in vagina and/or rectum, generally an asymptomatic condition, the infant is exposed to the bacteria during the passage in the birth canal. In an attempt to prevent GBS infection in neonates, most western countries have introduced programs for intrapartum antibiotic prophylaxis (IAP) (1, 2). The use of IAP has drastically reduced neonatal invasive GBS infections during the first week of life $(1,3)$. However, the increased use of antibiotics to women in labor has raised concerns about development of antibiotic resistance. For effective treatment and IAP it is important to monitor the prevalence of antibiotic resistance in GBS over time. Intravenous penicillin G is a first-choice drug for IAP and is given either to GBS colonized women or to women considered at risk. For treatment of established infections penicillin or ampicillin is often used in combination with an aminoglycoside as gentamicin (4). Streptococci are intrinsically resistant to aminoglycosides and not treatable with aminoglycosides given as single therapy. However, the combination of a cell-wall active antibiotic as penicillin or ampicillin and gentamicin has been shown to enhance killing of GBS (5). The synergistic effect between beta-lactam antibiotics and 
aminoglycosides is abolished if the isolate is high-level gentamicin resistant, a resistance mechanism best described in enterococci but also in a few GBS isolates $(6,7,8,9)$. GBS have long been considered as uniformly penicillin susceptible. Data regarding sporadic reports of isolates with phenotypically reduced susceptibility to penicillin have been difficult to interpret due to methological concerns and differences in recommended susceptibility breakpoints. However, two recent studies have reported alterations in the penicillin binding protein $2 X$ gene (pbp2x) in GBS leading to decreased penicillin susceptibility $(10,11)$.

The antibiotic most often used for IAP in case of penicillin allergy is clindamycin (12). Macrolides as erythromycin, clarithromycin and azithromycin have also been suggested as an alternative. The resistance rates for the macrolides-lincosamides-streptogramin $B\left(M_{B}\right)$ group of antibiotics in GBS exhibit geographic differences and vary over time $(13,14)$.

During 2005 a Swedish, population-based study of GBS carriage in parturients and infants, and risk factors for colonization, was performed before a regular national IAP program had been implemented (15). Of 1,569 mother/infant pairs examined the vaginal/rectal carriage rate of the mothers was $25,4 \%$. With phenotypic antibiotic susceptibility tests $5 \%$ of these isolates were found resistant to clindamycin and erythromycin. None of the isolates were resistant to penicillin $\mathrm{G}$ or showed high-level gentamicin resistance (15). In the present study 396 colonizing GBS were further examined for genetic resistance determinants of clindamycin, erythromycin, kanamycin, streptomycin and tetracycline.

\section{Material and methods}

GBS isolates $(n=396)$, were from a nationwide surveillance study conducted in Sweden during 2005 (15). The isolates were from vagina/rectum from parturient women, and from surface cultures from 44 newborns in whom the cultures from the mothers were negative. Since the surface cultures of the infants were taken immediately after birth, the vaginal samples in these mothers were assumed to be false negative. All GBS isolates were serotyped (types la, Ib, II-VIII) by co-agglutination (Essum AB, Umeå, Sweden) In non-typable isolates a PCR-based typing method was used (16). By multilocus sequence typing (MLST) a serotype III lineage, CC17, containing sequence type 17 (ST17), associated with neonatal invasive infections has been identified $(17,18)$. The presence of the mobile 
genetic elements GBSi1 and IS 1548 in serotype III isolates correlate with the phylogenetic lineages of further characterized by PCR for the presence of these mobile genetic elements. The serotypes of mother/infant pair isolates were congruent. The distribution of serotypes among the GBS was as follow: la 11\%, Ib 13\%, II 16\%, III 24\% (CC19 11\%, CC17 11\%), IV 15\%, V 19\%, VI 0.5\%, VII 1\%, and $0.5 \%$ non-typable. No serotype VIII isolates was found (15).

Phenotypic antibiotic susceptibility testing The isolates were cultured on blood agar plates containing Columbia agar base (Acumedia, Svenska Labfab, Ljusne, Sweden) and 5\% defibrinated horse blood and were identified as GBS as previously described (17). Disk diffusion was performed on Iso-Sensitest Agar (ISA) (Oxoid Ltd, Basingstoke, United Kingdom) with 5\% defibrinated horse blood and $20 \mathrm{mg} / \mathrm{L}$ of nicotinamide adenine dinucleotide (NAD) with a semi-confluent inoculum according to the Swedish Reference Group of Antibiotics (SRGA) (www.srga.org). Twenty-two isolates with MLS resistance and 24 isolates with oxacillin inhibitions zones less than $18.5 \mathrm{~mm}$ on ISA-NAD agar were also tested with the disk diffusion method that during 2010 will be recommended by the European Committee on Antimicrobial Susceptibility Testing (EUCAST) (www.eucast.org). In this method streptococci are tested on Mueller-Hinton agar (MH) supplemented with 5\% horse blood and $20 \mathrm{mg} / \mathrm{L}$ NAD with a confluent inoculum. Streptococcus pneumoniae ATCC 49619 was used for validation of the susceptibility tests. Screening for penicillin resistance was performed with $1 \mu \mathrm{g}$ oxacillin disks and with the EUCAST method also with $30 \mu \mathrm{g}$ ceftibuten disks. Minimum inhibitory concentrations (MICs) were tested with E-tests (AB Biodisk, Solna, Sweden). The plates were incubated for $18 \mathrm{~h}$ at $35^{\circ} \mathrm{C}$ in 5 $\% \mathrm{CO}_{2}$. To identify isolates with inducible $\mathrm{MLS}_{\mathrm{B}}$ resistance ( $\mathrm{iMLS}_{\mathrm{B}}$ ) the double-disk diffusion test with an erythromycin disk and a clindamycin disk, both of $15 \mu \mathrm{g}$, placed $25 \mathrm{~mm}$ apart was used. Flattening of the clindamycin growth inhibition zone indicate $\mathrm{MLS}_{\mathrm{B}}$. To screen for high-level aminoglycosideresistance disks prepared with $1000 \mu \mathrm{g}$ kanamycin and streptomycin respectively was used (8).

PCR amplification of resistance genes The occurrence of the tetracycline resistance genes tet $(\mathrm{O})$ and $\operatorname{tet}(\mathrm{M})$, the $M L S_{B}$ resistance genes $\operatorname{erm}(\mathrm{B}), \operatorname{erm}(\mathrm{A} / \mathrm{TR})$ and $\operatorname{mef}(\mathrm{A})$, and the genes aad- 6 and aphA-3 encoding aminoglycoside-modifying enzymes were determined with PCR according to Poyart et al (19). The aad-6 gene is also known as ant-6, and is coding for a streptomycin 
adenylyltransferase. DNA was extracted by the guanidium thiocyanate metod (20) for the PCR reactions with the aad- 6 and aphA-3 primers, for the other reactions the samples were boiled in water for $10 \mathrm{~min}$. The PCR mixtures of $50 \mu \mathrm{l}$ contained $0,2 \mu \mathrm{M}$ forward and reverse primers (DNA Technology A/S, Århus, Denmark), 1U of AmpliTaq Gold (Applied Biosystems, Stockholm, Sweden), $0.2 \mathrm{mM}$ of each deoxynucleoside triphosphate (Amersham Biosciences, Buckinghamshire, UK), 1.5 $\mathrm{mM} \mathrm{MgCl}_{2}$, and $100 \mathrm{ng}$ of template DNA in PCR buffer II with bovine serum albumin (Applied Biosystems). DNA amplification was carried out by initial denaturation at $95^{\circ} \mathrm{C}$ for 10 min and then cycling at $95^{\circ} \mathrm{C}$ for $1 \mathrm{~min}, 60^{\circ} \mathrm{C}$ for $30 \mathrm{~s}$, and $72^{\circ} \mathrm{C}$ for $30 \mathrm{~s}$ for 35 cycles, with a final incubation at $72^{\circ} \mathrm{C}$ for 5 min in a DNA Engine PTC-200 (MJ Research Inc., Watertown. Mass. USA). The amplicons were visualized by UV transillumination of ethidium bromide stained $1.75 \%$ agarose gels. PCR products were sequenced with the BigDye terminator cycle sequencing ready reaction kit (PE Applied Biosystems) on an ABI 377 (ABI prism sequencer, Applied Biosystems).

\section{Results}

Phenotypic tetracycline resistance was identified in 313 isolates (79\%). Every forth of these isolates were tested for the presence of tetO and tetM by PCR. In 89 of 94 isolates (94.7\%) tetM was found and in 3 of $94(3 \%)$ tetO. Neither tetO nor tetM could be identified in two of 94 isolates (2\%).

$\mathrm{MLS}_{\mathrm{B}}$ resistance was detected in 22 of the 396 isolates $(5,5 \%)$. According to the breakpoints for erythromycin from SRGA beta-haemolytic streptococci with growth-inhibition zones of $\geq 23 \mathrm{~mm}$ are interpreted as susceptible and isolates with zones $\leq 19 \mathrm{~mm}$ as resistant. Nineteen GBS met the criteria for intermediate susceptibility or resistance with disk diffusion on ISA-NAD agar and had erythromycin MICs $\geq 1 \mathrm{mg} / \mathrm{L}$ indicating resistance (Table I). No cut-off values for the disk diffusion have been determined by EUCAST, but with the use of the EUCAST method those 19 GBS had erythromycin inhibition zones $<18 \mathrm{~mm}$. In seven of these isolates a flattened clindamycin inhibition zone indicated iMLS ${ }_{B}$. The erm (A/TR) gene was amplified in all iMLS $S_{B}$ isolates and in three additional isolates, which lacked clindamycin inhibition zones. The ermB gene was identified in nine isolates (Table I). GBS with $M_{L} S_{B}$ resistance caused by an active efflux mediated by mef genes have been described. The Mphenotypes of such isolates, are erythromycin resistant and clindamycin susceptible without flattening of 
the clindamycin inhibition zone in the double diffusion test (21). The mef(A) gene could not be identified in any of the isolates of this study, which is in agreement with a lack of isolates with the M-phenotype. Neither erm (A/TR), ermB nor the mef(A gene could be identified in three isolates that were susceptible to erythromycin but with clindamycin inhibition zones $1.5-0.5 \mathrm{~mm}$ below the present breakpoint for resistance set at $24 \mathrm{~mm}$. The clindamycin MIC was $2 \mathrm{mg} / \mathrm{L}$, which indicated resistance, while the erythromycin MICs were low (Table I). Seven of the 64 serotype II isolates (11\%), five of 76 serotype V isolates $(7 \%)$ and six of 92 serotype III isolates $(6,5 \%)$ exhibited $\mathrm{MLS}_{\mathrm{B}}$ resistance but only single isolates of serotype la, Ib and IV. Four serotype V isolates harboring ermB, isolated from women from four different cities in Sweden, were the only isolates with MICs $>256 \mathrm{mg} / \mathrm{L}$ for both erythromycin and clindamycin. Tetracycline resistance was found in $89 \%$ of the 44 serotype III isolates that harbored the GBSi1 intron, corresponding to CC17 (17), but none of these isolates were erythromycin or clindamycin resistant.

All GBS had penicillin MICs $\leq 0.064 \mathrm{mg} / \mathrm{L}$ (15). The distribution of the inhibition zones from the screening of penicillin resistance with $1 \mu \mathrm{g}$ oxacillin disks suggested that all the isolates could belong to the wild type population (Table II). However, three GBS isolates gave inhibition zones $\leq 17 \mathrm{~mm}$, the breakpoint set by SRGA to guard for penicillin resistance in beta-haemolytic streptococci. The oxacillin MIC ${ }^{90}$ for the GBS isolates of the study was $1 \mathrm{mg} / \mathrm{L}$. The three isolates with oxacillin inhibitory zones repeatedly less than $17 \mathrm{~mm}$ (range 16.2-16.9 mm) were further tested and showed the following MICs: oxacillin $1 \mathrm{mg} / \mathrm{L}$, penicillin G 0,032-0,064mg/L, ampicillin 0,064-0,125mg/L, cefuroxime 0,064mg/L, cefotaxime 0,064 $0,125 \mathrm{mg} / \mathrm{L}$, imipenem $0,032-0.125 \mathrm{mg} / \mathrm{L}$ and cefoxitin $2-4 \mathrm{mg} / \mathrm{L}$. The identity of these isolates as GBS was confirmed with API-Strep (bioMériuex AB, Askim, Sweden). When tested with the EUCAST method the inhibition zone ranges of the three isolates were $15,7-18,5 \mathrm{~mm}$ and $16,2-19,2 \mathrm{~mm}$ for oxacillin and ceftibuten respectively, in agreement with results of the other isolates tested (Table II).

In 28 isolates with inhibitory zones for gentamicin of $\leq 8 \mathrm{~mm}$ the MICs ranged between 24-96 mg/L; i.e. $32-128 \mathrm{mg} / \mathrm{l}$ when the results are rounded up to the next highest twofold dilution, indicating that none of the isolates had high-level gentamicin resistance ( www.srga.org). One of these 28 isolates, which had a gentamicin MIC of $64 \mathrm{mg} / \mathrm{L}$, lacked an inhibition zone around the $1000 \mu \mathrm{g}$ kanamycin disk and harboured the aphA-3 gene. Four additional isolates, with gentamicin inhibition zones $>8 \mathrm{~mm}$, lacked 
inhibition zones around the highly loaded kanamycin disk and three of these also lacked inhibition zones around the $1000 \mu \mathrm{g}$ streptomycin disk (Fig 1). The kanamycin phosphorylase gene aphA-3 was present in all of the kanamycin resistant isolates. In addition the aad-6 gene, encoding a nucleotidyltransferase that adenylylate streptomycin, was identified in the three streptomycin resistant isolates. The kanamycin phosphorylas mediate resistance against amikacin as well and accordingly the amikacin MICs in all of the kanamycin resistant isolates were $>256 \mathrm{mg} / \mathrm{L}$. No zone around the $1000 \mu \mathrm{g}$ kanamycin disk is indicative for resistance. None of 20 isolates with kanamycin inhibition diameters ranging from 12 to 15 $\mathrm{mm}$ harboured the aphA-3 or aad- 6 gene. The 5 kanamycin resistant isolates were also macrolide resistant and had the erm(A/TR) gene (1 isolate) or the erm(B) gene (Table I).

\section{Discussion}

This study is, to our knowledge, the first report of high-level aminoglycoside resistance in GBS isolates from Scandinavia. Five of 396 GBS isolates (1.3\%) from a nation wide study of colonizing GBS were kanamycin and amikacin resistant. Screening with kanamycin $1000 \mu \mathrm{g}$ disks enabled a rapid and easy detection of these isolates. The breakpoint for the susceptible isolates was originally proposed as 17 $\mathrm{mm}$ (8). However, the distribution of the GBS population from this study suggests that a lower breakpoint, possibly at $12 \mathrm{~mm}$ would be more appropriate (Fig 1).

The kanamycin resistance gene aphA-3, present in these isolates, is in S. pneumoniae and Enterococcus faecalis located on transposons and plasmids, but the exact genetic organisation of the gene in these GBS isolates is not known. No isolates with high level gentamicin resistance was found. Despite this, keeping the evolution in enterococci in mind, in which several aminoglycoside modifying enzymes have been described (22), an active surveillance on the aminoglycoside resistance in GBS is warranted. The first gentamicin high level resistant (HLR) GBS, strain B128, was described in France in 1990 (6). The gene of the bifunctional aminoglycoside modifying enzyme Aac(6')-Aph (2') that mediate resistance to gentamicin and all other aminoglycosides besides streptomycin as well as homologes to aphA-3 and aad-6 genes was later identified in B128 (9). The aminoglycoside resistant determinants were carried by the transposon Tn3706 located on the chromosome. Tn3706 could be transposed from its chromosomal location onto the plasmid IP501, a conjugative multiple antibiotic resistance plasmid that can be transferred and stably maintained in a variety of Gram-positive genera, including GBS (23). However, the transposition lead to a structural instability of the plasmid and the 
authors concluded that pIP501-like plasmids probably do not constitute appropriate vectors for

Penicillin is the main choice for prophylaxis and therapy of GBS infections. The methodology used for the antibiotic susceptibility test is of vital importance when resistance data are interpreted. An additional important factor for the comparison of susceptibility among isolates is the breakpoints set for classification of isolates. Screening for penicillin resistance with $1 \mu \mathrm{g}$ oxacillin disks is recommended in Streptococcus pneumoniae and group A, B, C, and G streptococci by SRGA. The breakpoint to guard for penicillin resistance is at present set at $17 \mathrm{~mm}$. However, compared to the population distributions seen in pneumococci and group A, C, G streptococci, with a majority of isolates with oxacillin inhibition zones of 27-28 mm (www.srga.org), the GBS of this study exhibited inhibition zones with a mean zone size of $20 \mathrm{~mm}$ (Table II). This is in agreement with data, presented by Baker et al almost thirty years ago, which showed that higher penicillin concentrations were needed for growth inhibition and killing of GBS than for group A streptococci (5). The oxacillin breakpoint of $17 \mathrm{~mm}$ divides what seems to be a susceptible (native) GBS population and possibly could a breakpoint of 14 or $15 \mathrm{~mm}$ be more suited for GBS. The results of the oxacillin screening according to the EUCAST method were in agreement with that suggestion. Recently, high sensitivity and specificity for detection of reduced penicillin susceptibility in GBS was reported with a provisional cut off value of $20 \mathrm{~mm}$ for ceftibuten in disk diffusion (25). The tests were performed in accordance with the recommendation from the American Clinical and Laboratory Standards Institute (CLSI). From the results of our study a ceftibuten breakpoint for susceptibility of $\geq 15-16 \mathrm{~mm}$ seems to be more appropriate, a discrepancy possibly caused by the differences in methods used. However, studies on the alteration of Pbp genes in relation to penicillin susceptibility are needed to fully evaluate the isolates with smaller inhibition zones.

During 2008 a risk based program for IAP has been recommended by the National board of health in Sweden. Since this will lead to increased antibiotic use in the future it is of importance to follow the epidemiology of antibiotic resistance in GBS to be able to give guidance for the prophylaxis used. This is especially important when a risk based IAP program is used since no individual GBS isolates are 
cultured for examination of the antibiotic susceptibility in this regime. The overall degree of antibiotic resistance in the Swedish colonizing GBS isolates was low, with the exception for $79 \%$ resistance against tetracycline. Only $5 \%$ of the GBS were resistant to clindamycin, which can be compared to $\mathrm{MLS}_{\mathrm{B}}$ resistance rates around $15 \%$ in several European and Australian reports $(18,26)$, and $5-32 \%$ in the American continent $(8,27)$.

An increased degree of $M L S_{B}$ resistance in serotype $V$ isolates has been described $(19,26)$. This has also been shown in recent Swedish and Norwegian studies of invasive GBS isolates $(28,29)$. However, in this nation wide collection of colonizing GBS from parturient women no serotype dominated among the clindamycin and/or erythromycin resistant isolates. Whether the high-level of $\mathrm{MLS}_{\mathrm{B}}$ resistance found in the four serotype $\mathrm{V}$ isolates that carried the ermB gene indicate that they have an additional resistance mechanism has to be further evaluated.

The serotype III lineage, CC17, containing sequence type 17 (ST17), is strongly associated with neonatal invasive infections $(17,18)$. In a recent study serotype III isolates of ST17 were shown to carry less antibiotic resistance genes than the other GBS serotypes (14). The lack of $M L S_{B}$ resistance in this lineage was corroborated in our study.

We here provide a baseline description of resistance levels and resistance genes present among colonizing GBS in Sweden before implementation of a novel prophylactic regiment that will increase the use of intrapartum antibiotics. This kind of information will be useful in future evaluations of changes of resistance in GBS. We also suggest that a change of breakpoints for GBS oxacillin susceptibility tests should be considered. The results of this study partially disagree with some previous studies. We found no particular serotype to dominate among the $\mathrm{MLS}_{\mathrm{B}}$ resistant isolates. In contrast, other studies, in particular those that have included invasive isolates $(14,27,28)$, indicate serotype $\mathrm{V}$ to be predominant among the $\mathrm{MLS}_{\mathrm{B}}$ resistant GBS. In Norway an increase in fatality rate among neonates with GBS infection has been observed which coincided with an increase in $\mathrm{MLS}_{\mathrm{B}}$ resistance; predominantly in serotype $\mathrm{V}$ isolates (29). A possible explanation for the discrepancy between our study and others is that a clonal dissemination of $\mathrm{MLS}_{\mathrm{B}}$ resistant serotype $\mathrm{V}$ strains account for the increase among the invasive cases. We conclude that in this Swedish colonizing material, serotype $\mathrm{V}$ is a poor predictor of antibiotic resistance. However, the occurrence of high level erythromycin and clindamycin resistance found in all the four serotype $\mathrm{V}$ isolates containing the ermB gene merits further examination. In summary, among Swedish colonizing GBS isolates $5,5 \% \mathrm{MLS}_{\mathrm{B}}$ 
resistance and 1,3\% aminoglycoside resistance was found among the evenly distributed serotypes la to $\mathrm{V}$.

\section{Acknowledgments}

Åsa Hedlund and Helén Edebro for technical assistance.

This study was supported by a grant (ALF) from Västerbottens County Council.

\section{References}

1. Schrag SJ, Zywicki S, Farley MM, Reingold AL, Harrison LH, Lefkowitz LB, Hadler JL, Danila R, Cieslak PR, Schuchat A (2000) Group B streptococcal disease in the era of intrapartum antibiotic prophylaxis. N Engl J Med 342:15-20

2. Berardi A, Lugli L, Rossi C, Morini MS, Vagnarelli F, Ferrari F (2008) Group B streptococcus and preventive strategies in Europe. Arch Dis Child Fetal Neonatal Ed 93:F249.

doi:10.1136/adc.2007.135392

3. Law MR, Palomaki G, Alfirevic Z, Gilbert R, Heath P, McCartney C, Reid T, Schrag S (2005) The prevention of neonatal group B streptococcal disease: a report by a working group of the Medical Screening Society. J Med Screen 12:60-68

4. Isaacs D, Wilkinson AR (1987) Antibiotic use in the neonatal unit. Arch Dis Child 62:204-208

5. Baker CN, Thornsberry C, Facklam RR (1981) Synergism, killing kinetics, and antimicrobial susceptibility of group A and B streptococci. Antimicrob Agents Chemother 19:716-725 
6. Buu-Hoï A, Le Bouguenec C, Horaud T (1990) High-level chromosomal gentamicin resistance in Streptococcus agalactiae (group B). Antimicrob Agents Chemother 34:985-988

7. Liddy H, Holliman R (2002) Group B Streptococcus highly resistant to gentamicin. J Antimicrob Chemother 50:142-143

8. Lopardo HA, Vidal P, Jeric P, Centron D, Paganini H, Facklam RR, Elliott J; Argentinian Streptococcus Study Group (2003) Six-month multicenter study on invasive infections due to group B streptococci in Argentina. J Clin Microbiol 41:4688-4694

9. Kaufhold A, Podbielski A, Horaud T, Ferrieri P (1992) Identical genes confer high-level resistance to gentamicin upon Enterococcus faecalis, Enterococcus faecium, and Streptococcus agalactiae. Antimicrob Agents Chemother 36:1215-1218

10. Kimura K, Suzuki S, Wachino J, Kurokawa H, Yamane K, Shibata N, Nagano N, Kato H, Shibayama K, Arakawa Y (2008) First molecular characterization of group B streptococci with reduced penicillin susceptibility. Antimicrob Agents Chemother 52:2890-2897

11. Dahesh S, Hensler ME, Van Sorge NM, Gertz RE Jr, Schrag S, Nizet V, Beall BW (2008) Point mutation in the group B streptococcal pbp2x gene conferring decreased susceptibility to beta-lactam antibiotics. Antimicrob Agents Chemother 52:2915-2918

12. Schrag S, Gorwitz R, Fultz-Butts K, Schuchat A (2002) Prevention of perinatal group B streptococcal disease. Revised guidelines from CDC. MMWR Recomm Rep 51:1-22

13. Andrews JI, Diekema DJ, Hunter SK, Rhomberg PR, Pfaller MA, Jones RN, Doern GV (2000) Group B streptococci causing neonatal bloodstream infection: antimicrobial susceptibility and serotyping results from SENTRY centers in the Western Hemisphere. Am J Obstet Gynecol 183:859862 
14. Zhao Z, Kong F, Zeng X, Gidding HF, Morgan J, Gilbert GL (2008) Distribution of genotypes and antibiotic resistance genes among invasive Streptococcus agalactiae (group B streptococcus) isolates from Australasian patients belonging to different age groups Clin Microbiol Infect 14:260-267

15. Håkansson S, Axemo P, Bremme K, Bryngelsson AL, Wallin MC, Ekström CM, Granlund M, Jacobsson B, Källén K, Spetz E, Tessin I; Swedish Working Group For The Prevention of Perinatal Group B Streptococcal Infections (2008) Group B streptococcal carriage in Sweden: a national study on risk factors for mother and infant colonisation. Acta Obstet Gynecol Scand 87:50-58

16. Kong F, Gowan S, Martin D, James G, Gilbert GL (2002) Serotype identification of group B streptococci by PCR and sequencing. J Clin Microbiol 40:216-26.)

17. Luan SL, Granlund M, Sellin M, Lagergård T, Spratt BG, Norgren M (2005) Multilocus sequence typing of Swedish invasive group B streptococcus isolates indicates a neonatally associated genetic lineage and capsule switching. J Clin Microbiol 43:3727-3733

18. Jones N, Bohnsack JF, Takahashi S, Oliver KA, Chan MS, Kunst F, Glaser P, Rusniok C, Crook DW, Harding RM, Bisharat N, Spratt BG (2003) Multilocus sequence typing system for group B streptococcus. J Clin Microbiol 41:2530-2536

19. Poyart C, Jardy L, Quesne G, Berche P, Trieu-Cuot P (2003) Genetic basis of antibiotic resistance in Streptococcus agalactiae strains isolated in a French hospital. Antimicrob Agents Chemother 47:794-797

20. Boom R, Sol CJ, Salimans MM, Jansen CL, Wertheim-van Dillen PM, van der Noordaa J (1990) Rapid and simple method for purification of nucleic acids. J Clin Microbiol 28:495-503.

21. Arpin C, Daube H, Tessier F, Quentin C (1999) Presence of mefA and mefE genes in Streptococcus agalactiae. Antimicrob Agents Chemother 43:944-946 
22. Chow JW (2000) Aminoglycoside resistance in enterococci. Clin Inf Dis 31:586-589

23. Horaud T, de Céspèdes G, Trieu-Cuot $P$ (1996) Chromosomal gentamicin resistance transposon Tn3706 in Streptococcus agalactiae B128. Antimicrob Agents Chemother 40:1085-1090

24. Cooper MD, Keeney RE, Lyons SF, Cheatle EL (1979) Synergistic effects of ampicillinaminoglycoside combinations on group B streptococci. Antimicrob Agents Chemother 15:484-486

25. Kimura K, Wachino J, Kurokawa H, Suzuki S, Yamane K, Shibata N, Arakawa Y (2009) Practical disk diffusion test for detecting group B streptococcus with reduced penicillin susceptibility. J Clin Microbiol 47:4154-4157

26. Zeng X, Kong F, Wang H, Darbar A, Gilbert GL (2006) Simultaneous detection of nine antibiotic resistance-related genes in Streptococcus agalactiae using multiplex PCR and reverse line blot hybridization assay. Antimicrob Agents Chemother 50:204-209

27. Phares CR, Lynfield R, Farley MM, Mohle-Boetani J, Harrison LH, Petit S, Craig AS, Schaffner W, Zansky SM, Gershman K, Stefonek KR, Albanese BA, Zell ER, Schuchat A, Schrag SJ; Active bacterial core surveillance/emerging infections program network (2008) Epidemiology of invasive group B streptococcal disease in the United States, 1999-2005. JAMA 299:2056-2065

28. Persson E, Berg S, Bergseng H, Berg K, Valsö-Lyng R, Trollfors B (2008) Antimicrobial susceptibility of invasive group B streptococcal isolates from south-west Sweden 1988-2001. Scand J Infect Dis 40:308-313

29. Bergseng H, Afset JE, Radtke A, Loeseth K, Lyng RV, Rygg M, Bergh K (2009) Molecular and phenotypic characterization of invasive group B streptococcus strains from infants in Norway 20062007. Clin Microbiol Infect 15:1182-1185 
Figure 1.

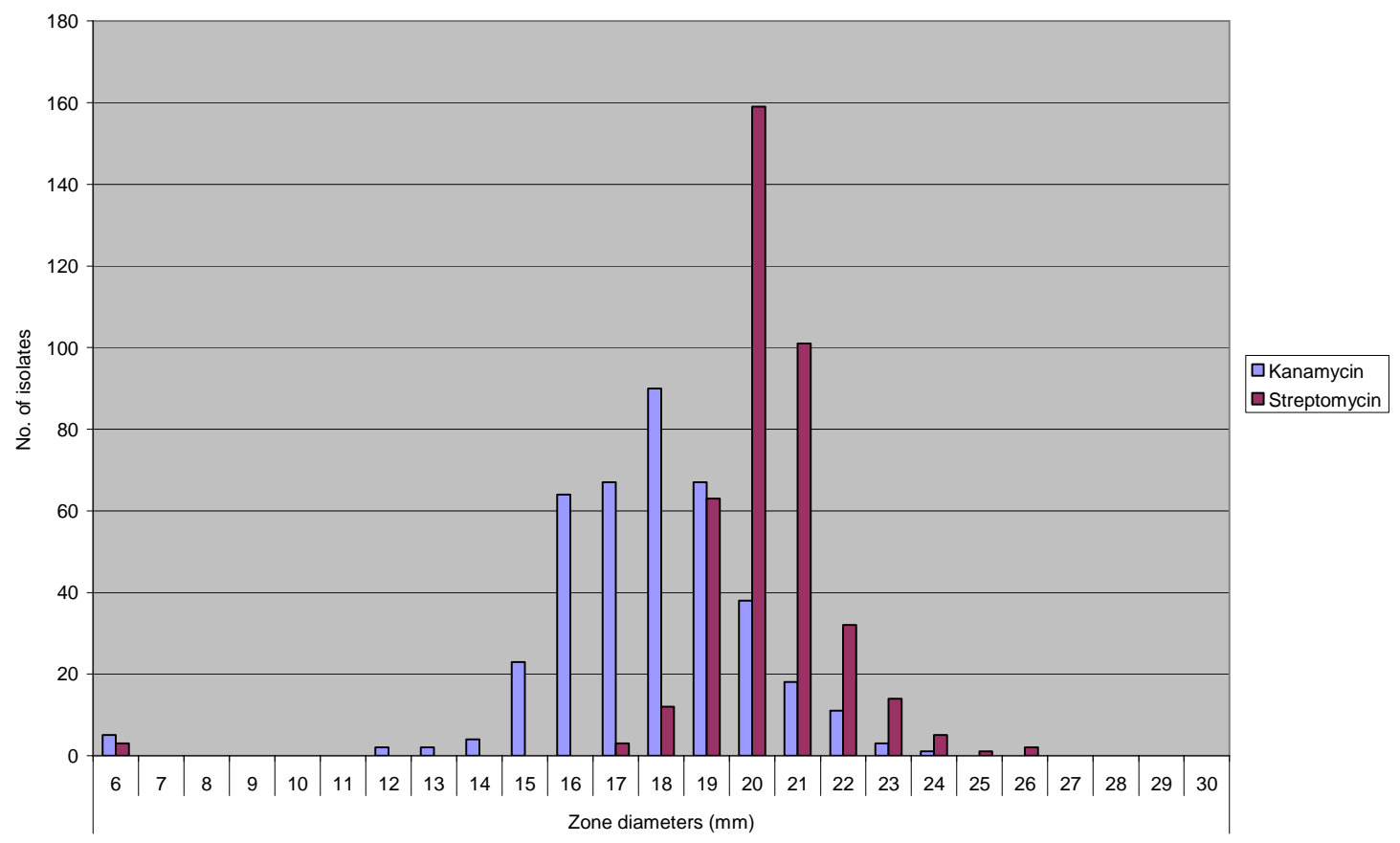

Fig.1. Zone diameter distributions for $1000 \mu \mathrm{g}$ disks of kanamycin and streptomycin against 396 group B streptococci. 
Table I

\begin{tabular}{|c|c|c|c|c|c|c|c|c|c|c|c|c|}
\hline \multirow[t]{2}{*}{$\begin{array}{l}\text { Sample } \\
\text { number }\end{array}$} & \multicolumn{5}{|c|}{ Resistance genes } & \multicolumn{4}{|c|}{ Disk-diffusion, inhibition zones (mm) } & \multicolumn{3}{|c|}{ Etest, MIC (mg/L) } \\
\hline & aad-6 & aphA-3 & erm B & erm A/TR & mefA & $E$ & DA & $\mathbf{E}$ & DA & EM & $\mathbf{C M}$ & Serotype \\
\hline 2321 & pos & pos & pos & neg & neg & 12.8 & 17.3 & 11.9 & 14 & 2 & 0.5 & III \\
\hline 2051 & neg & pos & pos & neg & neg & 14.2 & 21.1 & 11.1 & 12.8 & 2 & 0.5 & II \\
\hline 1944 & pos & pos & pos & neg & neg & 15 & 19.3 & 12.5 & 14.3 & 4 & 0.5 & II \\
\hline 302 & neg & pos & pos & neg & neg & 13.8 & 16.2 & 12.3 & 14.2 & 4 & 0.5 & III \\
\hline 2655 & & & pos & neg & neg & 6 & 23.7 & 6 & 21 & $>256$ & 1 & III \\
\hline 1057 & & & pos & neg & neg & 6 & 6 & 6 & 6 & $>256$ & $>256$ & V \\
\hline 1540 & & & pos & neg & neg & 6 & 6 & 6 & 6 & $>256$ & $>256$ & V \\
\hline 3066 & & & pos & neg & neg & 6 & 6 & 6 & 6 & $>256$ & $>256$ & V \\
\hline 2920 & & & pos & neg & neg & 6 & 6 & 6 & 6 & $>256$ & $>256$ & $\mathrm{~V}$ \\
\hline 18188 & pos & pos & "neg & pos & "neg & 20.1 & 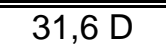 & "10.8 & 22,7D & 1 & 0.25 & "III \\
\hline 3107 & & & neg & pos & neg & 19.8 & $33,5 \mathrm{D}$ & 12.6 & $23,4 \mathrm{D}$ & 1 & 0.12 & III \\
\hline 2988 & & & neg & pos & neg & 15 & $31,2 \mathrm{D}$ & 12.9 & $29,5 \mathrm{D}$ & 2 & 0.12 & II \\
\hline 1456 & & & neg & pos & neg & 15.5 & $31,9 \mathrm{D}$ & 11.8 & $28,0 \mathrm{D}$ & 4 & 0.12 & II \\
\hline 2107 & & & neg & pos & neg & 16.7 & $32,4 \mathrm{D}$ & 11.8 & $17,3 \mathrm{D}$ & 4 & 0.12 & V \\
\hline 846 & & & neg & pos & neg & 17.7 & $34,8 \mathrm{D}$ & 12.8 & $30,1 \mathrm{D}$ & 4 & 0.12 & la \\
\hline 2280 & & & neg & pos & neg & 20.2 & $32,6 \mathrm{D}$ & NT & NT & NT & NT & III \\
\hline 2710 & & & neg & pos & neg & 18.6 & 6 & 17 & 6 & 4 & $>256$ & II \\
\hline 1511 & & & neg & pos & neg & 21.3 & 6 & 17.2 & 6 & 4 & $>256$ & la \\
\hline 2040 & & & neg & pos & neg & 13.9 & 6 & 6 & 6 & 8 & $>256$ & $\mathrm{lb}$ \\
\hline 2292 & & & neg & neg & neg & 29.1 & 23.5 & 27.8 & 24 & 0.12 & 2 & $\overline{I I I}$ \\
\hline 2225 & & & neg & neg & neg & 30.4 & 23.1 & 26.8 & 23.5 & 0.12 & 2 & II \\
\hline 865 & & & neg & neg & neg & 31 & 22.5 & 26.8 & 22.8 & 0.25 & 2 & IV \\
\hline
\end{tabular}

The genes aad- 6 and aphA-3 encode aminoglycoside-modifying enzymes.

The genes erm $(\mathrm{B})$, erm $(\mathrm{A} / \mathrm{TR})$ and $\operatorname{mef}(\mathrm{A})$ mediate resistance to the macrolides-lincosamides-streptogramin $\mathrm{B}$ group of antibiotics.

ISA-NAD is Iso-Sensitest Agar with $5 \%$ blood and $20 \mathrm{mg} / \mathrm{L}$ of nicotinamide adenine dinucleotide.

$\mathrm{MH}-\mathrm{NAD}$ is Mueller-Hinton agar with $5 \%$ horse blood and $20 \mathrm{mg} / \mathrm{L}$ nicotinamide adenine dinucleotide

E and EM: erythromycin

DA and CM:clindamycin 
Table II

\begin{tabular}{|c|c|c|c|c|c|}
\hline Oxacillin & \multicolumn{3}{|c|}{ Penicillin G MIC (Number of isolates) } & Oxacillin & Ceftibuten \\
\hline $\begin{array}{l}\text { ISA-NAD } \\
(\mathrm{mm})\end{array}$ & $0,016 \mathrm{mg} / \mathrm{L}$ & $0,032 \mathrm{mg} / \mathrm{L}$ & $0,064 \mathrm{mg} / \mathrm{L}$ & $\begin{array}{l}\text { MH-NAD } \\
(\mathrm{mm})\end{array}$ & $\begin{array}{l}\text { MH-NAD } \\
(\mathrm{mm})\end{array}$ \\
\hline $16,3-16,9$ & 0 & 0 & 3 & $15,7-18,5$ & $16,2-19,2$ \\
\hline $17,7-18,4$ & 0 & 10 & 11 & $16,1-20,7$ & $16,9-20,5$ \\
\hline $18,5-19,4$ & 0 & 71 & 44 & NT & NT \\
\hline $19,5-20,4$ & 2 & 73 & 33 & NT & NT \\
\hline $20,5-21,4$ & 0 & 68 & 18 & NT & NT \\
\hline $21,5-22,4$ & 7 & 38 & 2 & NT & NT \\
\hline $22,5-23,4$ & 1 & 10 & 0 & NT & NT \\
\hline $23,5-24,4$ & 1 & 0 & 0 & NT & NT \\
\hline $24,5-25,4$ & 2 & 1 & 0 & NT & NT \\
\hline
\end{tabular}

